\title{
A SHARP NORM INEQUALITY FOR NON-ISOTROPIC DISTANCE FUNCTIONS ON $\mathbf{R}^{n}$
}

\author{
FARUK F. ABI-KHUZAM AND BASSAM SHAYYA
}

Abstract. We obtain best possible upper and lower bounds for spherical means of distance functions associated with non-isotropic dilation groups on $\mathbf{R}^{n}$.

Mathematics subject classification (2000): 26B15, 26B10.

Key words and phrases: Non-isotropic distance functions, dilation groups.

\section{REFERENCES}

[1] B. SHAYYA, Singular integrals with nonhomogeneous oscillatory kernels, Indiana Univ. Math. J., 50 (2001), 1015-1025.

[2] E. M. STEIN And S. WAINGER, Problems in harmonic analysis related to curvature, Bull. Amer. Math. Soc. 84 (1978), 1239-1295. 